\title{
Physics in Industry at the Wembley Laboratories.
}

$\mathrm{T}$ HE General Electric Company, Ltd., is now a very large organisation, which employs some twenty thousand workers. It has engineering works at Birmingham, where it manufactures all kinds of electrical machines. At Stoke, near Coventry, telephones are manufactured. At the Osram lamp works at Hammersmith, lamps and valves of all kinds are made. At Erith, the company took over a few years ago the works of Messrs. Fraser and Chalmers, which manufacture steam turbines and mining plant. At Southampton, electric cables of all kinds are manufactured, and the company has glass works at Lemington-on-Tyne. Mainly on the initiative of Mr. Hugo Hirst, the managing director, it was decided some six years ago to establish a central laboratory to carry out the scientific and industrial researches which are essential for the progress of industry. Mr. Clifford Paterson, who was then the head of the electrotechnical department of the National Physical Laboratory, was appointed superintendent, and he is now helped by a staff of physicists and engineers many of whom have world-wide reputations.

The opening of the research laboratories on February 27 was a very interesting function. Lord Robert Cecil, speaking at the opening ceremony, said that the immediate task of the country is to repair the waste of the war. To do this the first and most essential requirement is to use every endeavour to increase the output of human energy and skill. This can only be done in two ways, namely, by reducing expenditure and by increasing the efficiency of production. Research, by making every man's skill go further, adds to the world's wealth. Science has no territorial boundaries. By promoting research the relations between this country and the world are improved. Sir J. J. Thomson, who also spoke, pointed out that it is absolutely necessary that a research laboratory should have a highly efficient staff. The capacity for the highest kind of research is rare. Training may increase the efficiency of a researcher, but it cannot put insight and originality into him. It is also certain that no research laboratory can guarantee delivery. The output of such a laboratory is always highly irregular and spasmodic. Sir Joseph Thomson also dwelt on the importance of cultivating the thinking powers of the community to the utmost.

The research laboratories are situated near Wembley and have a total floor area of 80,000 square feet, but they have ample room for expansion. The building has a north-light roof and nearly all of it is only one storey in height. The upper floor galleries carry most of the electric cables and the hydraulic pressure, steam, gas, and vacuum pipes required by the experimenters.

These galleries carry the arterial system essential for the laboratory without the necessity for conduits or ducts. This greatly increases the flexibility of the whole system.

The machinery in the central sub-station supplies the electric power, keeps the gases in circulation, and maintains the vacuum in the vacuum pipes throughout the building. Power at a pressure of $285^{\circ}$ volts and on the three-phase system is supplied by the North Metropolitan Electric Supply Co., and is converted into various pressures, both direct and alternating, for the distributing mains by means of motor generators and transformers. The lighting system is permanent, and is not touched for experimental purposes. The method of arranging the experimental distributing system is an extension of that which Mr. Paterson used at the National Physical Laboratory.
In addition to the electric machinery the substation contains the vacuum and compressor plant. Two rotary compressors feed into a horizontal boiler placed in the gallery, and this stores the compressed air which is required for experimental purposes. There are also three vacuum pumps driven by motors which are in continuous operation. These exhaust a fine vacuum main to the low pressure of $0.5 \mathrm{~mm}$. of mercury and rough vacuum mains to pressures down to $6 \mathrm{~mm}$. of mercury. There are also high-pressure hydraulic mains, compressed-air mains, and a oneinch hydrogen main.

There are two splendidly equipped workshops, one for metal and one for wood. These make the special apparatus required by the staff. They also engage in research work of their own, devising and improving automatic machinery and suggesting means of accelerating and improving the methods of production.

In the vacuum physics laboratory, X-ray analysis and analyses for detecting traces of gases are made. A novel question that is being investigated is the $\mathrm{X}$-ray danger that may exist in connexion with the use of valve tubes at high voltages. For example, when these tubes are being exhausted, pressures of Io,ooo volts and upwards are sometimes applied. Ordinary bulb glass which contains about i 8 per cent. of lead is impermeable to these rays, but the special silica tubes often used in valve work are permeable; it is therefore necessary to know whether the work is dangerous or not. The problems produced by the static charges and other high voltage effects produced in bulbs are also being studied.

Some of the laboratories, for example the one for measuring the life of lamps, are used for routine testing. There were 800 lamps undergoing life tests simultaneously. They were of all kinds, carbon filament, metal filament, neon lamps, etc. Some of the neon lamps produce very novel effects and they are in great demand at present in physical laboratories. In photometry the equipment is very complete, and the various problems of illumination are being investigated by most scientific methods. A novel photometer was shown in operation which measured the absorbing power of various surfaces for light. By the use of this instrument the "blackness" of the inside coatings of lamp bulbs tarnished by use can be measured.

A specially novel and interesting feature of the laboratories is that they contain four small experimental factories for making electric lamps, tungsten wire, thermionic valves, and primary batteries, and these laboratory factories are regarded as tools which any of the research staff can use in connexion with the further development of a research. It is inadvisable to specialise research to too great an extent. Lamp research, for example, is not confined to the intensely interesting work on vacuum physics. It is equally concerned with metallurgical research, glass research, radiation from solids and gases, and high tension electrical phenomena in general. In a research laboratory it is necessary that the staff should be interested in practically every kind of research.

Many other interesting researches are being carried out at Wembley, and some of the work done has already proved of great commercial value in the factory. The importance of physics in electrical development may be illustrated by the case of the ordinary switch for the electric lamp. In the old days, an ominous bluish light sometimes made its appearance when the switch was turned off, and occasionally a switch was burnt out. The base of 
the switch was sometimes made of wood, which is a very poor insulator. Electricians then improved matters by ascelerating the rate at which the terminal pieces separated when the current was broken. Later on it was found that a double air break was a vast improvement, and the base is now made of the best vitreous porcelain, which is practically a non-conductor. Those who use switches nowadays seldom if ever consider the thought that has been expended on their development. Every device in a progressive factory is undergoing continual improvement, and practical men recognise the value of an experimental and theoretical study of the physical laws which govern its development.

The new laboratory at Wembley is one of the largest research laboratories in this country. Compared with American standards, however, it is not large. The research laboratory of the Western Electric Co., Inc., of 463 West Street, New York, has a 13 -storey building on a floor area of 400,000 square feet, and employs i 600 full-time researchers under the able guidance of Dr. Jewett, president of the American Institution of Electrical Engineers. The results obtained, however, are seldom in proportion to the size of a research laboratory, and we were much impressed by the ability of the staff at Wembley.

\section{University and Educational Intelligence.}

ABERdEEN.-The honorary degree of LL.D. was conferred, in absentia, on the Duke of Richmond and Gordon, Chancellor of the University, at a meeting of the Senatus Academicus held on Tuesday, February $27^{\circ}$

Prof. W. Mitchell, vice-chancellor and Hughes professor of philosophy in the University of Adelaide, South Australia, has been appointed Gifford lecturer for the sessions $1924-25$ and $1925^{-26}$.

CAMBRIDGE.-The Grace approving the regulations for the admission of women students of Girton and Newnham Colleges to titular degrees in the University has now been approved and one stage of a long-drawnout controversy has been completed. Among the other privileges granted to women students by the new regulations is included the right to be admitted to instruction in the University and to University laboratories and museums, though the number receiving such instruction at any one time is limited to five hundred. Women are now admitted as research students on the same footing as present candidates for the degrees of M.Litt., M.Sc. and Ph.D.

The Right Hon. T. Clifford Allbutt, Gonville and Caius College, Regius professor of physic, has been appointed as delegate to the celebration next June of the 8ooth anniversary of the foundation of $\mathrm{St}$. Bartholomew's Hospital and the Priory Church of St. Bartholomew the Great.

THE opening of the new chemistry section of the Technical High School of Stockholm is announced in the Chemiker Zeitung of February Io. The building cost 3,300,00o kroner, and has four large laboratories for inorganic, organic, technical, and electrochemistry, and a smaller for the study of fermentation. The Director is Prof. W. Palmaer. It is stated that in size the building is exceeded only by that of Boston.

A REPORT on the development of adult education in rural areas has been issued (H.M. Stationery Office, $6 d$.) by the Adult Education Committee constituted in April I92 I by the Board of Education. The report reviews the work in this field of existing organisations-Local Education and other County Authorities, Women's Institutes, University Extersion Committees, Workers' Educational Association, Association of Village Clubs, Y.M.C.A., Educational Settlements, and County Unions of village organisations, - the conditions of State aid, and the available sources of supply of books, and concludes with several practical suggestions. Among the opinions formulated by the Committee are: schemes of rural education properly organised can secure immediate and notable success provided village initiative and co-operation are encouraged; some form of county organisation, such as the Oxford Rural Community Council, is essential; national organisation is desirable and has been provided for by the recent establishment of a representative council by the National Council of Social Service; pioneer lectures and short courses of lectures are a necessary prelude to formal classes and merit State aid; the full development of the Carnegie Trust Rural Library Scheme will solve most difficulties as to the supply of books. As regards this last point, it is explained in a highly interesting memorandum appended to the report that it is the policy of the trustees to promote the establishment of county schemes controlled by County Council Education Committees, and 192,00ol. was set aside by the trustees in February 1920 to enable every county to inaugurate one. By January 1922 thirty-eight were in operation. The key-stone of the whole system is the Central Library for Students (London and Dunfermline), from which any goodclass modern book on a serious subject can be obtained through the county librarians.

Statistics of 670 Universities, Colleges, and Professional Schools, published by the United States Bureau of Education as Bulletin, 1922, No. 28, shows a total student cnrolment for I9I9-20 of $52 \mathrm{I}, 754$, of whom rather more than one-third were women; by departments-preparatory 59,309, collegiate 34I,082, graduate I5,6I2, professional 57, I3I. Of the $67^{\circ}$ institutions, Iog were under public and $56 \mathrm{I}$ under private control: 82 were independent professional schools. Of $5^{86}$ universities and colleges with undergraduate students, 354 were co-educational, and reported $162,55^{8}$ men and 96,908 women; II 7 were maintained exclusively for men and II 5 exclusively for women. Enrolments in the professional schools were: law 20,992, medicine 14,242 , dentistry 8809 , theology 7216 , pharmacy 5026 , veterinary medicine 908. The percentage of women students ranged between $\mathrm{I}_{4}$ in pharmacy and $\mathrm{O} \cdot \mathrm{OI}$ in veterinary medicine. Engineering schools enrolled 5I,908 students, almost all men, distributed as follows general engineering Io,23I, civil 8859, mechanical I 1,789 , electrical 9469 , mining 3048 , chemical 5743 . The number of engineering students more than doubled itself in the decade roro-20. The total amount of benefactions - excluding government grants-was 65 million dollars. The total income per student-363 dollars in 1920 -has risen steadily since I 890 , when it was only 68 dollars. During the same period the percentage of receipts derived from the Federal Government, the State, and the city has increased from 12 to 27 and of student fees from 22 to 26 , while the percentage from productive funds and private benefactions has decreased from 65 to 38 . The following figures relate to universities and university colleges (excluding Oxford and Cambridge) in Great Britain in receipt of annual Treasury grants in $1920-21$ : income per student $54 l$., percentage of income from endowments $I I$, parliamentary grants 34 , grants from local authorities 9, tuition fees 32 .

NO. 2784 , VOL. I I I] 